\title{
Vitamin D deficiency and non-lipid biomarkers of cardiovascular risk
}

Kamil F. Faridi1,2, Joshua R. Lupton², Seth S. Martin², Maciej Banach³, Renato Quispe², Krishnaji Kulkarni ${ }^{4}$, Steven R. Jones², Erin D. Michos²

\author{
${ }^{1}$ Division of Cardiovascular Disease, Beth Israel Deaconess Medical Center, Boston, \\ MA, USA \\ ${ }^{2}$ Ciccarone Center for Prevention of Heart Disease, Johns Hopkins University, \\ Baltimore, MD, USA \\ ${ }^{3}$ Department of Hypertension, Chair of Nephrology and Hypertension, Medical \\ University of Lodz, Lodz, Poland \\ ${ }^{4}$ Atherotech Diagnostics Laboratory, Birmingham, AL, USA
}

Submitted: 1 February 2017

Accepted: 11 February 2017

Arch Med Sci 2017; 13, 4: 732-737

DOI: https://doi.org/10.5114/aoms.2017.68237

Copyright $\odot 2017$ Termedia \& Banach

\section{Abstract}

Introduction: Deficient 25-hydroxyvitamin D (25(OH)D) levels have been associated with dyslipidemia and cardiovascular diseases, though the underlying mechanism of these associations is uncertain. We analyzed associations between vitamin $\mathrm{D}$ and other non-lipid biomarkers of cardiovascular risk to better elucidate possible relationships between deficient $25(\mathrm{OH}) \mathrm{D}$ and cardiovascular disease.

Material and methods: We performed a cross-sectional analysis of 4,591 adults included in a clinical laboratory database from 2009 to 2011 with available measurements for $25(\mathrm{OH}) \mathrm{D}$ and the following biomarkers: homocysteine (Hcy), high-sensitivity C-reactive protein (hs-CRP), cystatin-C, creatinine, $\gamma$-glutamyltransferase (GGT), uric acid, and hemoglobin $A_{1 c}\left(H b A_{1 c}\right)$. We calculated odds ratios (OR) of having high levels of each biomarker associated with $25(\mathrm{OH}) \mathrm{D}$ deficiency $(<20 \mathrm{ng} / \mathrm{ml})$ compared to optimal levels $(\geq 30 \mathrm{ng} / \mathrm{ml}$ ) using logistic regression adjusted for age, sex, and lipids.

Results: The mean \pm SD age was $60 \pm 14$ years and $46 \%$ of patients were women. In multivariable-adjusted models, adults with deficient $25(\mathrm{OH}) \mathrm{D}$ compared to those with optimal levels had increased odds of elevated biomarkers as follows: Hcy (OR $=2.53,95 \% \mathrm{Cl}: 1.92-3.34)$, hs-CRP (1.62, $1.36-1.93)$, cystatin-C $(2.02,1.52-2.68)$, creatinine $(2.06,1.35-3.14)$, GGT (1.39, 1.07-1.80), uric acid (1.60, 1.31-1.95), and $\mathrm{HbA}_{1 \mathrm{c}}(2.47,1.95-3.13)$. In analyses evaluating women and men separately, 25(OH)D deficient women but not men had increased odds of elevated levels of all biomarkers studied. There were significant interactions based on sex between $25(\mathrm{OH}) \mathrm{D}$ and $\mathrm{Hcy}$ $(p=0.003)$, creatinine $(p=0.004)$, uric acid $(p=0.040)$, and $\mathrm{HbA}_{1 c}(p=0.037)$. Conclusions: Deficient 25(OH)D is associated with elevated levels of many biomarkers of cardiovascular risk, particularly among women, in a United States population.

Key words: vitamin D, cardiovascular risk, biomarkers.

\section{Introduction}

Vitamin D deficiency is a common condition that affects over $40 \%$ of the United States population [1]. Deficiency in 25-hydroxyvitamin D

\author{
Corresponding author: \\ Kamil F. Faridi MD \\ Division of \\ Cardiovascular Disease \\ Beth Israel Deaconess \\ Medical Center \\ West Campus, Baker 4 \\ 185 Pilgrim Road \\ Boston, MA 02215, USA \\ Phone: 617667800 \\ Fax: 6176679369 \\ E-mail: kfaridi@bidmc. \\ harvard.edu
}


$(25(\mathrm{OH}) \mathrm{D})$, the most widely used measure of vitamin D status, has been independently associated with risk of cardiovascular disease, severity of coronary atherosclerosis, and all-cause mortality [2-4]. However, clinical trials have not definitively shown that treatment of $25(\mathrm{OH}) \mathrm{D}$ deficiency with supplementation improves cardiovascular outcomes, and it remains uncertain why these associations exist [5]. The association between vitamin $D$ deficiency and cardiovascular risk may be explained by underlying pathophysiologic mechanisms which have not been fully elucidated. We previously found that low 25(OH)D is associated with an atherogenic lipid profile $[6,7]$. We now evaluate whether 25(OH)D deficiency is associated with other biomarkers of cardiovascular risk in a single study cohort, the Very Large Database of Lipids (VLDL-3B) Study.

\section{Material and methods}

We used the Very Large Database of Lipids (VLDL), a dataset of 1,340,614 U.S. adults who were referred for Vertical Auto Profile (VAP) ultracentrifugation lipid analysis from 2009 to 2011 [8]. We studied 4,591 individuals who had available measurements for 25(OH)D, homocysteine (Hcy), high-sensitivity C-reactive protein (hs-CRP), cystatin- $C$, creatinine, $\gamma$-glutamyltransferase (GGT), uric acid, and hemoglobin $\mathrm{A}_{1 \mathrm{c}}\left(\mathrm{HbA}_{1 \mathrm{c}}\right)$.

Total 25(OH)D was measured using the LIASON 25(OH) Vitamin D Reagent Integral: Ref 310600 kit and Liaison chemistry analyzer (DiaSorin). Direct measurements of high-density lipoprotein cholesterol (HDL-C), total cholesterol (TC), nonHDL-C, and low-density lipoprotein cholesterol (LDL-C) were conducted using inverted rate zonal single vertical spin, density gradient ultracentrifugation by the VAP technique. Triglycerides (TG) were measured with the Abbott ARCHITECT C-8000 system (Abbott Park, IL). Hcy and cystatin $C$ were measured using marker-specific reagents manufactured by Diazyme Laboratories (Poway, CA) and the Architect clinical chemistry analyzer (Abbott Laboratories, Abbott Park, IL). Creatinine, GGT, and uric acid were measured using marker-specific reagent and Architect clinical chemistry analyzer manufactured by Abbott Laboratories

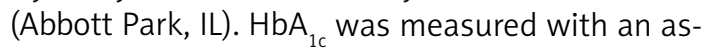
say based on the AxSym chemistry analyzer and an immunoassay reagent (Abbott Diagnostics). The methodology was changed on 07/20/2010 to one based on the Tosoh Automated Glycohemoglobin Analyzer and G8 Variant Elution Buffer No. 1 (S), No. 2 (S), and No. 3 (S) (Tosoh Corporation). As is typical for a laboratory dataset, other clinical characteristics such as body mass index, physical activity levels, and medication/supplement usage were not available.
Atherotech Diagnostics Lab recorded patient data as part of routine clinical measurements, removed duplicates, and de-identified data before transfer to investigators. The database is housed at the Johns Hopkins Hospital in Baltimore, Maryland. All investigators had unrestricted access to the data and authority over the manuscript. The Johns Hopkins University School of Medicine Institutional Review Board granted the study an exemption from informed consent.

We examined the distribution of demographics and biomarkers across the following clinical cutoff levels of $25(\mathrm{OH}) \mathrm{D}$ defined by the Endocrine Society guidelines [9]: deficient $(<20 \mathrm{ng} / \mathrm{ml})$, intermediate $(\geq 20-30 \mathrm{ng} / \mathrm{ml})$, and optimal $(\geq 30 \mathrm{ng} / \mathrm{ml})$. To convert 25(OH)D levels from $\mathrm{ng} / \mathrm{ml}$ to $\mathrm{nmol} / \mathrm{l}$, multiply by 2.496 . Elevated non-lipid biomarkers were defined as follows: Hcy $(\geq 18.6 \mu \mathrm{mol} / \mathrm{l})$, hs-CRP $(\geq 2.0 \mathrm{mg} / \mathrm{l})$, cystatin-C $(\geq 1.65 \mathrm{mg} / \mathrm{l})$, creatinine $(\geq 1.5 \mathrm{mg} / \mathrm{dl})$, GGT $(\geq 73 \mathrm{U} / \mathrm{l})$, uric acid ( $\geq 6$ (women), $\geq 7$ (men) $\mathrm{mg} / \mathrm{dl}$ ), and $\mathrm{HbA}_{1 \mathrm{c}}$ $(\geq 6.5 \%)$. We conducted logistic regressions to determine the odds of elevated non-lipid biomarker levels for deficient (compared to optimal) 25(OH)D groups after adjustment for age, sex, HDL-C, directly measured LDL-C, and TG. We also tested for interactions by sex and age based on 25(OH)D status.

\section{Statistical analysis}

Statistical analyses were generated using Stata version 12.0 (College Station, TX).

\section{Results}

Our study population consisted of 4,591 individuals with a mean \pm SD age of $60 \pm 14$ years, and $46 \%$ were women. The clinical characteristics of individuals with deficient, intermediate, and optimal 25(OH)D are shown as median and interquartile range in Table I. After using multivariable adjustment to account for age, sex, LDL-C, TG, and HDL-C, increased odds of elevated biomarkers for $25(\mathrm{OH}) \mathrm{D}$ deficient individuals persisted for all variables (Figure 1): Hcy (OR = 2.53, 95\% Cl: 1.92-3.34), hs-CRP (1.62, 1.36-1.93), cystatin-C $(2.02,1.52-2.68)$, creatinine $(2.06,1.35-3.14)$, GGT $(1.39,1.07-1.80)$, uric acid (1.60, 1.31-1.95), and $\mathrm{HbA}_{1 \mathrm{c}}(2.47,1.95-$ 3.13). We performed separate analyses adjusting for age, sex, and non-HDL-C and obtained similar results ( $p<0.001$ for all variables).

We performed separate analyses stratified by sex and age. Among women, in multivariable-adjusted analyses, 25(OH)D deficiency compared to optimal levels was associated with increased odds of elevated levels of all biomarkers studied: Hcy $(\mathrm{OR}=3.89,95 \% \mathrm{Cl}: 2.52-5.99)$, hs-CRP (1.57, $1.22-2.03)$, cystatin-C $(2.02,1.33-3.08)$, creatinine $(4.14,1.88-9.13)$, GGT $(1.72,1.16-2.55)$, 
Table I. Distribution of variables by clinical categories of $25(\mathrm{OH}) \mathrm{D}^{\dagger \neq}$

\begin{tabular}{|c|c|c|c|}
\hline Parameter & $\begin{array}{c}\text { Deficient 25(OH)D } \\
<20 \mathrm{ng} / \mathrm{ml}(n=850)\end{array}$ & $\begin{array}{c}\text { Intermediate } 25(\mathrm{OH}) \mathrm{D} \\
\geq 20-30 \mathrm{ng} / \mathrm{ml}(n=1430)\end{array}$ & $\begin{array}{c}\text { Optimal 25(OH)D } \\
\geq 30 \mathrm{ng} / \mathrm{ml}(n=2311)\end{array}$ \\
\hline Age [years] & $58(48-68)$ & $59(50-69)$ & $62(53-71)$ \\
\hline Sex (\% female) & 50.8 & 44.0 & 46.4 \\
\hline $\mathrm{Hcy}[\mu \mathrm{mol} / \mathrm{l}]$ & $11.6(9-15.6)$ & $11(9-14.6)$ & $10.7(8.7-13.7)$ \\
\hline hs-CRP [mg/l] & $2.8(1.3-6.3)$ & $2.1(0.9-4.6)$ & $1.5(0.7-3.7)$ \\
\hline Cystatin-C [mg/l] & $1.07(0.93-1.32)$ & $1.07(0.93-1.28)$ & $1.07(0.93-1.28)$ \\
\hline Creatinine [mg/dl] & $0.9(0.8-1.0)$ & $0.9(0.8-1.0)$ & $0.9(0.8-1.0)$ \\
\hline GGT [U/I] & $31(21-53)$ & $30(20-44)$ & $26(18-39)$ \\
\hline Uric acid [mg/dl] & $5.6(4.6-6.7)$ & $5.6(4.5-6.6)$ & $5.1(4.1-6.2)$ \\
\hline $\mathrm{HbA}_{1 \mathrm{c}}(\%)$ & $5.8(5.5-6.3)$ & $5.7(5.5-6.1)$ & $5.7(5.4-6.0)$ \\
\hline $\mathrm{HDL}-\mathrm{C}[\mathrm{mg} / \mathrm{dl}]$ & $46(39-56)$ & $49(40-59)$ & $52(43-65)$ \\
\hline $\mathrm{TC}[\mathrm{mg} / \mathrm{dl}]$ & $197(164-230)$ & $185(159-216)$ & $175(148-208)$ \\
\hline Non-HDL-C [mg/dl] & $148(117-179)$ & $134(109-163)$ & $118.5(94-150)$ \\
\hline LDL-C [mg/dl] & $119(91-147)$ & $108.5(85-135)$ & $97(76-125)$ \\
\hline Triglycerides [mg/dl] & $145(102-213)$ & $126(89-183)$ & $103(74-148)$ \\
\hline
\end{tabular}

${ }^{\dagger}$ Except for sex, values are median (interquartile range). $H b A_{1 c}-$ hemoglobin $A_{1 c}$ BUN - blood urea nitrogen, $H D L-C-$ high-density lipoprotein cholesterol, TC - total cholesterol, LDL-C - low-density lipoprotein cholesterol; "to convert 25(OH)D levels from ng/ml to $\mathrm{nmol} / \mathrm{l}$, multiply by 2.496 .

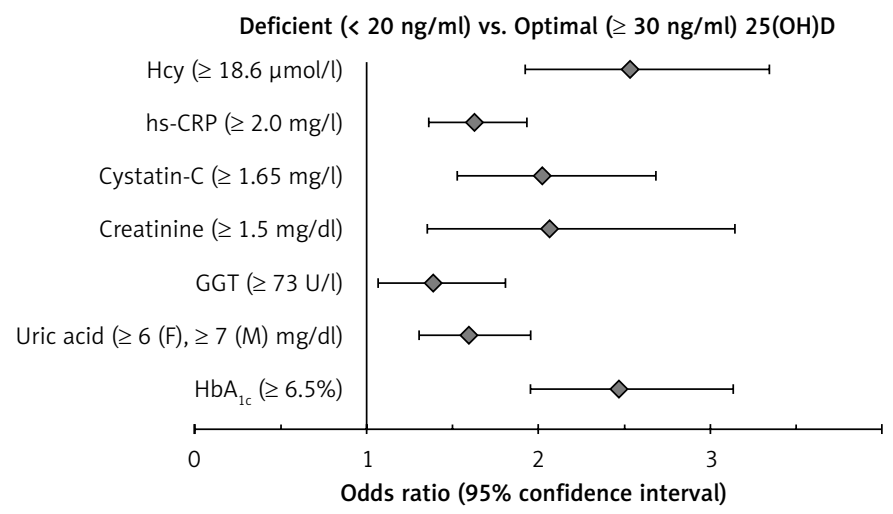

Figure 1. Adjusted ${ }^{\dagger}$ odds ratios of elevated ${ }^{\ddagger}$ biomarkers in vitamin D deficient compared to optimal individuals ${ }^{\dagger}$ Odds ratios were adjusted for age, sex, total cholesterol, directly measured LDL cholesterol, triglycerides, and HDL cholesterol. ${ }^{\ddagger}$ Elevated serum risk biomarkers were defined as follows ( $n=\#$ of individuals with elevated levels out of total population of 4591): homocysteine $\geq 90^{\text {th }}$ percentile $=18.6 \mu \mathrm{mol} / \mathrm{l}(n=469)$, $\mathrm{hs}-C R P \geq 2 \mathrm{mg} / \mathrm{l}(\mathrm{n}=2281)$, cystatin- $\mathrm{C} \geq 90^{\text {th }}$ percentile $=$ $1.65 \mathrm{mg} / \mathrm{l}(\mathrm{n}=462)$, creatinine $\geq 1.5 \mathrm{mg} / \mathrm{dl}(\mathrm{n}=194), G G T \geq 90^{\text {th }}$ percentile $=73 \mathrm{U} / \mathrm{l}(\mathrm{n}=465)$, uric acid $\geq 7 \mathrm{mg} / \mathrm{dl}(\mathrm{men}) \mathrm{or} \geq 6 \mathrm{mg} / \mathrm{dl}$ (women) $(n=992), H b A_{1 c} \geq 6.5 \%(n=640)$.

uric acid (2.02, 1.50-2.72), and $\mathrm{HbA}_{1 \mathrm{c}}(2.90,2.02-$ 4.15). However, in men, there was a non-significant trend for associations with four out of seven biomarkers: cystatin-C $(1.51,0.96-2.37)$, creatinine $(1.45,0.86-2.46)$, GGT $(1.10,0.66-1.58)$, and uric acid (1.30, 0.99-1.72), but three biomarkers remained statistically significant: Hcy $(1.73,1.19$ 2.52), hs-CRP (1.70, 1.34-2.16), and $\mathrm{HbA}_{1 \mathrm{c}}$ (2.14, 1.56-2.95) (Figure 2). We tested for interactions between 25(OH)D and each biomarker based on sex and found significant interactions for Hcy ( $p=0.003)$, creatinine $(p=0.004)$, uric acid
( $p=0.040)$, and $\mathrm{HbA}_{1 c}(p=0.037)$. In interaction testing based on age, we found a significant interaction for hs-CRP ( $p=0.029)$ but not for any other biomarkers.

\section{Discussion}

In this study we found that $25(\mathrm{OH}) \mathrm{D}$ deficiency is associated with increased levels of multiple non-lipid biomarkers of cardiovascular risk. This relationship was observed for all biomarkers included in our study and persisted after adjustment for age, sex, and lipids. We also found a trend towards 

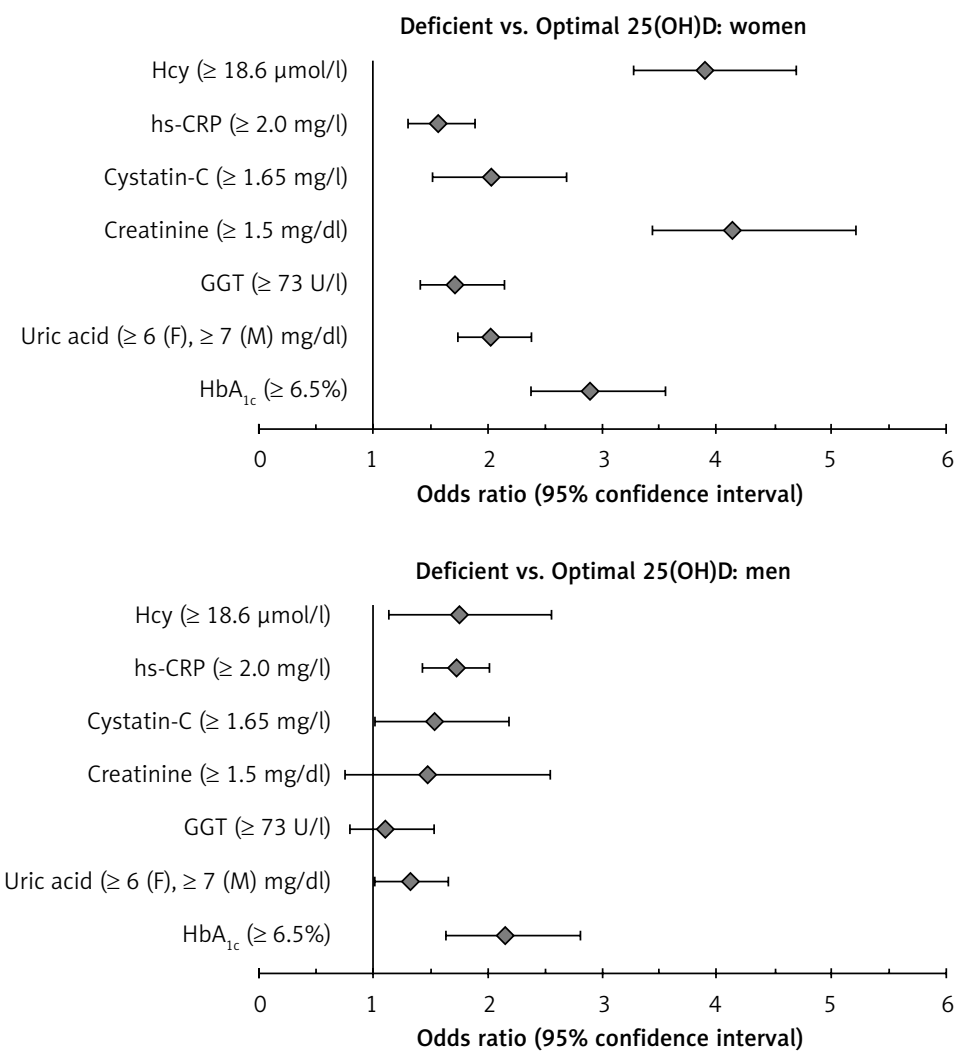

Figure 2. Adjusted ${ }^{\dagger}$ odds ratios of elevated ${ }^{\ddagger}$ biomarkers in vitamin D deficient compared to optimal individuals by sex

${ }^{\dagger}$ Odds ratios were adjusted for age, total cholesterol, directly measured LDL cholesterol, triglycerides, and HDL cholesterol. "Elevated serum risk biomarkers were defined as follows: homocysteine $\geq 90^{\text {th }}$ percentile $=18.6 \mu \mathrm{mol} / \mathrm{l}, \mathrm{hs}-\mathrm{CRP} \geq 2 \mathrm{mg} / \mathrm{l}$, cystatin- $C \geq 90^{\text {th }}$ percentile $=1.65 \mathrm{mg} / \mathrm{l}$, creatinine $\geq 1.5 \mathrm{mg} / \mathrm{dl}, \mathrm{GGT} \geq 90^{\text {th }}$ percentile $=73 \mathrm{U} / \mathrm{l}$, uric acid $\geq 7 \mathrm{mg} / \mathrm{dl}$ (men) or $\geq 6 \mathrm{mg} / \mathrm{dl}$ (women), $H b A_{1 c} \geq 6.5 \%$.

increased odds of higher biomarkers for women compared to men, with significant interactions for $\mathrm{Hcy}$, creatinine, uric acid, and $\mathrm{HbA}_{1 \mathrm{c}}$ based on sex. Several studies have shown that $25(\mathrm{OH}) \mathrm{D}$ deficiency was associated with increased levels of several of the variables we analyzed, such as homocysteine, renal function, uric acid, and $\mathrm{HbA}_{1 \mathrm{c}}$ [10-14]. However, to the best of our knowledge, this analysis is the first to evaluate the association between $25(\mathrm{OH}) \mathrm{D}$ and such an extensive panel of risk biomarkers in a single cohort of this size, and to show potential differences by sex.

Deficiency in $25(\mathrm{OH}) \mathrm{D}$ has been consistently associated with risk of myocardial infarction and cardiovascular death in multiple studies [4, 15], though the reason for this observation is unclear. The relationship between vitamin D and cardiovascular disease may be explained by mechanisms involving inflammation, the renin-angiotensin-aldosterone system, insulin sensitivity, or vascular calcification [16-22]. Alternatively, it is also possible that this association may be confounded by other variables related to overall health status including physical activity, sunlight exposure, and obesity [23-25]. Our work suggests that the association between $25(\mathrm{OH}) \mathrm{D}$ deficiency and cardio- vascular risk may be related to a particular at-risk phenotype rather than one particular risk factor. Given that women appear to have increased odds of having elevated levels of several risk biomarkers compared to men, there may be additional sex-related factors such as hormones that influence the relationship between $25(\mathrm{OH}) \mathrm{D}$ deficiency and other cardiovascular risk factors.

Our study results should be considered in the context of several limitations. Our study is cross-sectional, therefore our results are limited to the associations between variables and do not prove a causal relationship between $25(\mathrm{OH}) \mathrm{D}$ deficiency and the biomarkers we evaluated. The demographic and clinical information available in our data set also did not include variables such as race, body mass index, and comorbid conditions which may have impacted the relationships we observed.

In conclusion, deficient $25(\mathrm{OH}) \mathrm{D}$ is associated with elevated levels of multiple non-lipid cardiovascular risk biomarkers in a cross-sectional U.S. population. These associations were stronger in women than in men. Further studies are needed to explore the relationship between $25(\mathrm{OH}) \mathrm{D}$ and other biomarkers to determine whether these as- 
sociations may influence long-term cardiovascular risk and whether treating vitamin D deficiency can lead to improvement in these biomarkers.

\section{Conflict of interest}

K.F. Faridi, J.R. Lupton, M. Banach, R. Quispe have no relevant disclosures to report. S.S. Martin has served as a consultant to Pressed Juicery, Abbott Nutrition, Quest Diagnostics, Sanofi/Regeneron, and the Pew Research Center, outside the scope of this article. Dr. Martin has been the recipient of prior or pending grants associated with Aetna Foundation, the American Heart Association, and Google, outside the scope of this article. Dr. Martin is listed as a co-inventor on a pending patent for a method of LDL-C estimation, not used in this article. K. Kulkarni received a salary as an employee of Atherotech and a modest royalty from the University of Alabama at Birmingham. S.R. Jones is listed as a co-inventor on a pending patent for a method of LDL-C estimation, not used in this article. Dr. Jones has received a charitable gift for support for the VLDL project from the David and June Trone Family Foundation. E.D. Michos has no disclosures to report relevant to this study. Unrelated to this study, Dr. Michos has served as a consultant for Siemens Diagnostic, Inc. as a blinded adjudicator of coronary events for a clinical trial.

\section{Funding}

We did not receive any specific funding for the preparation of this article. Dr. Michos is supported by NIH/NINDS grant R01NS072243 for vitamin D research and by the Blumenthal Scholars Fund in Preventive Cardiology. Dr Martin has grant support from the PJ Schafer Cardiovascular Research Fund, American Heart Association, Aetna Foundation, and Google, outside the scope of this article. The Very Large Database of Lipids project is funded by the David and June Trone Family Foundation.

\section{Role of data sponsor}

Atherotech provided the investigators with de-identified data generated from commercial lipid analyses and did not provide payments for the research or manuscript writing and did not participate in data analysis or influence the conclusions. This study was initiated by the investigators and did not receive any specific funding. The authors take responsibility for the accuracy of the statistical analyses and had the sole authority on manuscript preparation and submission for publication.

\section{References}

1. Forrest KY, Stuhldreher WL. Prevalence and correlates of vitamin D deficiency in US adults. Nutr Res 2011; 31: 48-54.
2. Wang L, Song Y, Manson JE, et al. Circulating 25-hydroxy-vitamin $D$ and risk of cardiovascular disease: a meta-analysis of prospective studies. Circ Cardiovasc Qual Outcomes 2012; 5: 819-29.

3. Dziedzic EA, Przychodzen S, Dabrowski M. The effects of vitamin $D$ on severity of coronary artery atherosclerosis and lipid profile of cardiac patients. Arch Med Sci 2016; 12: 1199-206.

4. Lutsey PL, Michos ED. Vitamin D, calcium, and atherosclerotic risk: evidence from serum levels and supplementation studies. Curr Atheroscler Rep 2013; 15: 293.

5. Manson JE, Bassuk SS. Vitamin D research and clinical practice: at a crossroads. JAMA 2015; 313: 1311-2.

6. Lupton JR, Faridi KF, Martin SS, et al. Deficient serum 25-hydroxyvitamin $D$ is associated with an atherogenic lipid profile: the Very Large Database of Lipids (VLDL-3) study. J Clin Lipidol 2016; 10: $72-81$ e1.

7. Faridi KF, Zhao D, Martin SS, et al. Serum vitamin D and change in lipid levels over 5 years: the Atherosclerosis Risk in Communities (ARIC) study. Nutrition 2017; ePub ahead of print.

8. Martin SS, Blaha MJ, Toth PP, et al. Very large database of lipids: rationale and design. Clin Cardiol 2013; 36: 641-8.

9. Holick MF, Binkley NC, Bischoff-Ferrari HA, et al. Evaluation, treatment, and prevention of vitamin $D$ deficiency: an Endocrine Society clinical practice guideline. J Clin Endocrinol Metab 2011; 96: 1911-30.

10. Blondon $M$, Cushman $M$, Jenny $N$, et al. Associations of serum 25-hydroxyvitamin $D$ with hemostatic and inflammatory biomarkers in the multi-ethnic study of atherosclerosis. J Clin Endocrinol Metab 2016; 101: 2348-57.

11. Melamed ML, Astor B, Michos ED, Hostetter TH, Powe NR, Muntner P. 25-hydroxyvitamin D levels, race, and the progression of kidney disease. J Am Soc Nephrol 2009; 20: 2631-9.

12. Kositsawat J, Freeman VL, Gerber BS, Geraci S. Association of A1c levels with vitamin D status in U.S. adults: data from the National Health and Nutrition Examination Survey. Diabetes Care 2010; 33: 1236-8.

13. Amer M, Qayyum R. The relationship between 25-hydroxyvitamin $\mathrm{D}$ and homocysteine in asymptomatic adults. J Clin Endocrinol Metab 2014; 99: 633-8.

14. Alemzadeh R, Kichler J. Uric acid-induced inflammation is mediated by the parathyroid hormone: 25 -hydroxyvitamin $D$ ratio in obese adolescents. Metab Syndr Relat Disord 2016; 14: 167-74.

15. Michos ED, Misialek JR, Selvin E, et al. 25-hydroxyvitamin $D$ levels, vitamin $D$ binding protein gene polymorphisms and incident coronary heart disease among whites and blacks: the ARIC study. Atherosclerosis 2015; 241: 12-7.

16. Al Mheid I, Patel RS, Tangpricha V, Quyyumi AA. Vitamin $\mathrm{D}$ and cardiovascular disease: is the evidence solid? Eur Heart J 2013; 34: 3691-8.

17. Ilincic B, Stokic E, Stosic Z, et al. Vitamin D status and circulating biomarkers of endothelial dysfunction and inflammation in non-diabetic obese individuals: a pilot study. Arch Med Sci 2017; 13: 53-60.

18. Mazidi M, Michos ED, Banach M. The association of telomere length and serum 25-hydroxyvitamin D levels in US adults: the National Health and Nutrition Examination Survey. Arch Med Sci 2017; 13: 61-5.

19. Akbas EM, Gungor A, Ozcicek A, Akbas N, Askin S, Polat $M$. Vitamin $D$ and inflammation: evaluation with neutrophil-to-lymphocyte ratio and platelet-to-lymphocyte ratio. Arch Med Sci 2016; 12: 721-7. 
20. Dinca M, Serban MC, Sahebkar A, et al.; Lipid Blood Pressure Meta-analysis Collaboration LG. Does vitamin D supplementation alter plasma adipokines concentrations? A systematic review and meta-analysis of randomized controlled trials. Pharmacol Res 2016; 107: 360-71.

21. Li YC, Kong J, Wei M, Chen ZF, Liu SQ, Cao LP. 1,25-Dihydroxyvitamin $\mathrm{D}(3)$ is a negative endocrine regulator of the renin-angiotensin system. J Clin Invest 2002; 110: 229-38.

22. de Boer $I H$, Kestenbaum B, Shoben AB, Michos ED, Sarnak MJ, Siscovick DS. 25-hydroxyvitamin D levels inversely associate with risk for developing coronary artery calcification. J Am Soc Nephrol 2009; 20: 1805-12.

23. Vimaleswaran KS, Berry DJ, Lu C, et al. Causal relationship between obesity and vitamin D status: bi-directional Mendelian randomization analysis of multiple cohorts. PLoS Med 2013; 10: e1001383.

24. Chin K, Zhao D, Martin SS, et al. Abstract 17767: Physical activity, vitamin $\mathrm{D}$, and incident atherosclerotic cardiovascular disease in the Atherosclerosis Risk in Communities (ARIC) Study. Circulation 2016; 134: A17767.

25. Donneyong MM, Taylor KC, Kerber RA, Hornung CA, Scragg R. Is outdoor recreational activity an independent predictor of cardiovascular disease mortality - NHANES III? Nutr Metab Cardiovasc Dis 2016; 26: 735-42. 